Article

\title{
Predicting the Future Manufacturing Cost of Batteries for Plug-In Vehicles for the U.S. Environmental Protection Agency (EPA) 2017-2025 Light-Duty Greenhouse Gas Standards
}

\author{
Michael J. Safoutin *, Joseph McDonald and Ben Ellies \\ U.S. Environmental Protection Agency, Washington, DC, USA; McDonald.Joseph@epa.gov (J.M.); \\ Ellies.Ben@epa.gov (B.E.) \\ * Correspondence: Safoutin.Mike@epa.gov; Tel.: +1-734-214-4300
}

Received: 17 July 2018; Accepted: 26 September 2018; Published: 6 October 2018

check for updates

\begin{abstract}
In developing the U.S. 2017-2025 Light-Duty Vehicle Greenhouse Gas Emissions Standards, the U.S. Environmental Protection Agency (EPA) modeled lithium-ion battery packs for future electrified vehicles to estimate their direct manufacturing costs through 2025. As part of the 2016 Midterm Evaluation of the standards for model years (MY) 2022 to 2025, the analysis was revised to account for developments in battery design since the 2012 rulemaking. This paper describes the methodology that was used for estimating battery capacity, power, and cost, and compares the projected cost estimates to other sources. An empirical equation is derived for specifying motor power as a function of target acceleration time, and suggested factors for converting cell-level costs to pack-level costs are developed.
\end{abstract}

Keywords: lithium battery; cost; prediction; vehicle performance; modeling

\section{Introduction}

The 2017-2025 Light-Duty Vehicle Greenhouse Gas Emissions Standards [1] were finalized in 2012 and represent a significant action to reduce greenhouse gas emissions. The rulemaking process included an accounting of the cost of meeting the standards. EPA studied the incremental cost of many advanced automotive technologies, including plug-in electric vehicles (PEVs), a category that includes battery electric vehicles (BEVs) and plug-in hybrid electric vehicles (PHEVs [2-4]. Because much of the cost of a PEV is in the cost of the battery, it was necessary to develop a robust and transparent methodology for projecting battery costs for these vehicles. Battery costs have many drivers, and regardless of the methodology, future projections are subject to uncertainty. It is, therefore, important to consider the methodology and assumptions when assessing the validity of cost projections as conditions evolve over time.

At the time of the EPA final rulemaking (FRM) in 2012, the task of specifying plug-in vehicle batteries for arbitrary combinations of vehicle size, power, and range was a difficult task. At the time, few production vehicles were available either to establish the current state of technology or to suggest the rate of its future advancement. Accordingly, our methodology employed a wide variety of simplifying assumptions and estimation methods to conduct the effort in a practical way while using calculation tools that are easily accessible to external reviewers [3]. This paper details the methodology by which we projected future battery performance specifications and costs for MY 2025, including key input assumptions derived from ongoing study of the emerging industry from 2012 through 2016. 


\section{Materials and Methods}

\subsection{Structure of Analysis}

The battery cost analysis described here was only one component of a much broader analysis that modeled the cost and effectiveness of many efficiency-improving technologies, including not only electrification but also advanced internal combustion engine, transmission, and road load reduction technologies, among others. Potential penetrations of these technologies were projected across 29 different vehicle types (as described at page 1-37 of [3]) to demonstrate how a cost-minimizing compliant fleet could be achieved at various points in the timeframe of the rule and at what cost. The technology packages considered included several types of PEVs having various targets for range, power, and mass reduction. The battery cost analysis was one step in assigning cost to these vehicles through MY 2025.

As shown in Figure 1, the battery cost analysis began by defining an array of PEVs for which lithium-ion battery packs would be specified and costs determined. This included five PEV types of various ranges (75-mile BEV75, 100-mile BEV100, 200-mile BEV200, 20-mile PHEV20, and 40-mile PHEV40), six baseline vehicle classes having different power and curb weight targets, and five levels of target curb weight reduction ( $0,2,7.5,10$, and 20 percent). This resulted in a total of 150 PEV instances [3]. A battery sizing spreadsheet converted each vehicle's range target and mass-reduced curb weight to a target battery and motor power $(\mathrm{kW})$ and a target gross battery capacity $(\mathrm{kWh})$. The sizing spreadsheet was dynamically linked to the Battery Performance and Cost (BatPaC) model developed by Argonne National Laboratory (ANL) [5], which provided specific energy ( $\mathrm{kWh} / \mathrm{kg}$ ) estimates for use by the sizing algorithm and direct manufacturing costs for each battery pack. For more detail on the sizing algorithm see pp. 2-359 of [3].

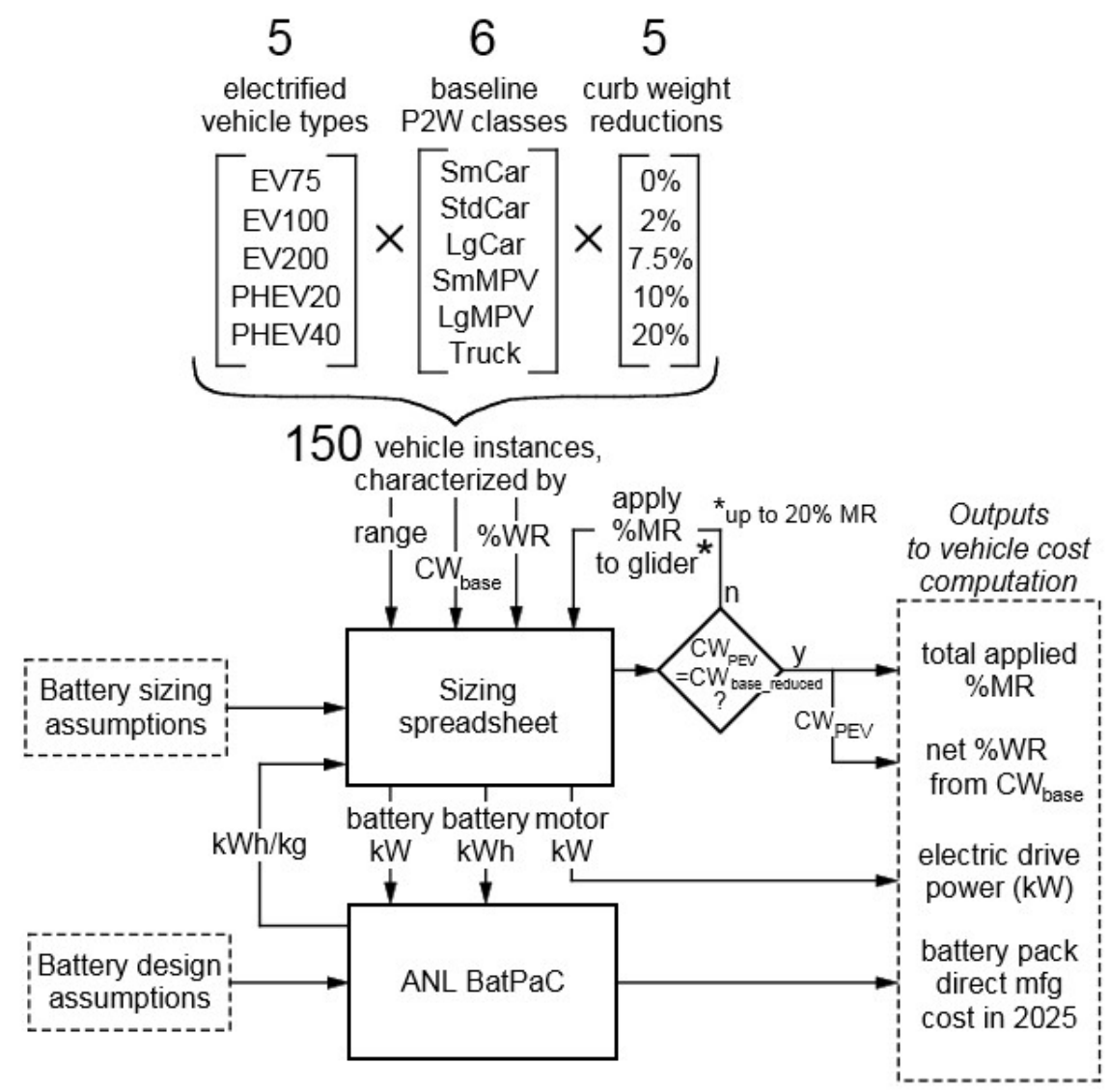

Figure 1. Analysis structure for vehicle battery sizing and cost estimation. Key: P2W, power-to-weight class; CW, curb weight; WR, curb weight reduction; MR, glider mass reduction. 


\subsection{Calculation Method}

The battery cost analysis is a spreadsheet-based methodology. An important first step in the analysis is to estimate battery energy capacities and power requirements for the vehicles to be modeled. Because capacity and power requirements are strongly influenced by vehicle weight, and battery weight is both a function of and a contributor to vehicle weight, sizing the battery requires an iterative solution. This problem is well suited to the iteration function available in common spreadsheet software [3]. The use of a spreadsheet also makes the analysis easily accessible to public inspection. To this end, further detail on the choice of inputs to this analysis [3] and access to spreadsheets used in the analysis [6] are available.

BatPaC [5] is a spreadsheet-based lithium-ion battery costing model developed by ANL. It employs a rigorous, bottom-up, bill-of-materials approach to battery cost analysis. User inputs to BatPaC include performance goals (power and energy capacity), choice of battery chemistry (for example, Lithium Manganese oxide (LMO) or several varieties of Nickel Manganese Cobalt oxide $(\mathrm{NMC})$ ), the vehicle type for which the battery is intended (e.g. PHEV or BEV), the desired number of cells and modules and their layout in the pack, and the volume of production. BatPaC then designs the electrodes, cells, modules, and pack, and provides a complete, itemized cost breakdown [3]. From this perspective, the main task in specifying a PEV battery pack is to determine the energy storage capacity $(\mathrm{kWh})$ and power capability $(\mathrm{kW})$ that are needed to provide a desired driving range and level of acceleration performance [3].

The battery cost model upon which BatPaC was based was described in a paper presented at EVS-24 [7]. ANL later extended the model to include detailed analysis of manufacturing costs for many types of PEVs [8]. EPA arranged for an independent peer review of the BatPaC model in 2011 [9]. We used Version 3.0 of BatPaC, provided to EPA on 17 December 2015. EPA continues to work closely with ANL to test new versions of $\mathrm{BatPaC}$ and to guide the development of new features [3].

BatPaC models stiff-pouch, laminated prismatic format cells, placed in double-seamed, rigid modules. The model supports liquid- and air-cooling, accounting for the resultant structure, volume, cost, and heat rejection capacity. It takes into consideration the cost of capital equipment, plant area and labor for each step in the manufacturing process and places relevant limits on electrode coating thickness and other limits applicable to current and near-term manufacturing processes. It also considers annual pack production volume and economies of scale for high-volume production [3].

\subsection{Basis of Battery and Motor Power Specification}

An initial step was to assign targets for peak powertrain power based on desired acceleration performance. A commonly cited metric for acceleration performance is the time needed for a vehicle to accelerate from zero to 60 miles per hour, also known as "0-60" time. At the time of the FRM in 2012, EPA's annual Trends Report [10] had customarily used an equation by Malliaris et al. [11] to estimate 0-60 time as a function of the ratio of rated engine power to equivalent test weight (ETW). Because this relationship was derived from the behavior of internal combustion powertrains, we investigated its applicability to the torque-delivering behavior of electric drive by surveying the peak motor power ratings and acceleration performance of electrified vehicles present in the market between 2012 and 2017 and capable of pure electric 0-60 acceleration. As shown in Figure 2, comparing the empirical data for PEVs (shown by the thin orange line) to the Malliaris equation (heavy black line) showed that use of the Malliaris equation would have resulted in much higher power specification than necessary, and would have led to overestimation of the cost of the motor and the battery pack. 


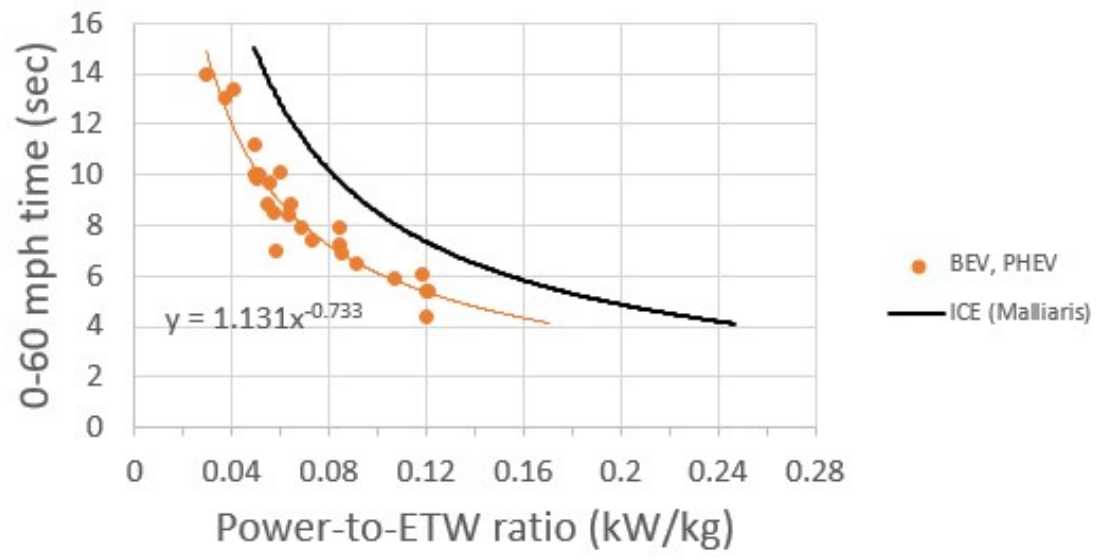

Figure 2. Relationship between peak-power-to-ETW ratio and acceleration performance for MY 2012-17 PEVs capable of pure electric acceleration.

We used an empirical fit of the PEV data plotted in Figure 2 to derive a new Equation (1) to relate more accurately the ETW and rated peak power of an electric powertrain $(\mathrm{kW})$ to $0-60$ time (t, in sec). While the exact relationship of rated power to acceleration would also depend on the gear ratio of the final drive, the basis of the equation on empirical data suggests that suitable ratios exist and could be chosen accordingly by the manufacturer.

$$
t=1.1321\left(\frac{\mathrm{kW}}{\mathrm{kg} \mathrm{ETW}}\right)^{-0.733}
$$

Motor power for each vehicle was assigned using this equation, beginning with the baseline ETW and a target 0-60 time between 8.35 and $11 \mathrm{~s}$ depending on vehicle class. Because the needed power of the motor and battery interacts with battery and vehicle weight, the power calculation must be performed iteratively by the spreadsheet as part of the overall battery sizing process [3]. Because PHEV20 was modeled as a blended architecture with engine assist, the motor power for these vehicles was set to half of the total required power to represent the availability of engine assist, although we acknowledge that vehicle designs may vary in this regard. Battery power was derived from motor power as described later in Section 2.5.1.

\subsection{Basis of Battery Energy Capacity Assignment}

The next step was the specification of battery capacity needed for a given driving range. Range was modeled as a real-world, EPA-label, 5-cycle fuel economy range by applying a derating factor to an estimated EPA 2-cycle range. For BEVs, range was considered a beginning-of-life criterion, in accordance with EPA range labeling practice. For PHEVs, however, manufacturers are likely to consider mitigating loss of electric range because it will affect the utility factor, a component in the calculation of $\mathrm{CO}_{2}$ emissions over useful life. The PHEV sizing algorithm therefore reserves a buffer to be used as the battery ages, as described later in Section 2.5.1.

Battery capacity also depends on the vehicle energy consumption rate. This depends largely on vehicle weight, road load, component efficiencies, and other factors. The process for estimating energy consumption for each PEV was as follows. First its curb weight was estimated as equal to the curb weight $\mathrm{CW}_{\text {base }}$ of the corresponding baseline conventional vehicle, modified by any applicable curb weight reduction $W R_{\text {target }}$ (representing a curb weight reduction of $0,2,7.5,10$, or 20 percent), and further modified by deletion of the weight of conventional powertrain components (for BEVs) and addition of electric content (for BEVs and PHEVs), as shown in Equations (2) through (5) [3].

$$
\mathrm{WR}_{\text {target }}=\% \mathrm{WR} * \mathrm{CW}_{\text {base }}
$$




$$
\begin{gathered}
\mathrm{CW}_{\text {base_reduced }}=\mathrm{CW}_{\text {base }}-\mathrm{WR}_{\text {target }} \\
\mathrm{CW}_{\mathrm{BEV}}=\mathrm{CW}_{\text {base_reduced }}-\mathrm{W}_{\mathrm{ICE} \_ \text {powertrain }}+\mathrm{W}_{\text {electric_content }} \\
\mathrm{CW}_{\mathrm{PHEV}}=\mathrm{CW}_{\text {base_reduced }}+\mathrm{W}_{\text {electric_content }}
\end{gathered}
$$

The curb weights $\mathrm{CW}_{\text {base }}$ of conventional baseline vehicles were assigned based on average weights for each of the six vehicle classes defined in the EPA baseline fleet that was generated for the broader analysis. The divisions among the classes, being based in part on power-to-weight ratio, are referred to here as "P2W class". The P2W classes thereby establish target baseline curb weights and power requirements as inputs.

The weight of conventional powertrain components that would not exist on a battery electric

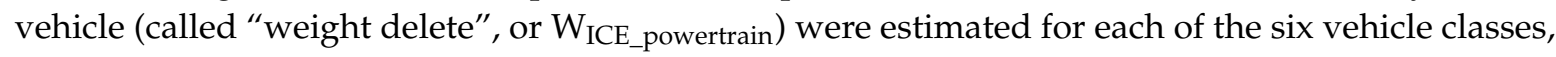
as an approximate function of power. The weight of electric components $\left(\mathrm{W}_{\text {electric_content }}\right)$ included an estimated weight for the electric drive (motor and power electronics) as well as the weight of the battery. The weight of this content is computed iteratively by the spreadsheet, because it is strongly influenced by the total weight of the vehicle as well as several other factors. Electric drive weight was based on the targets established by US DRIVE [12] for the specific power of traction motors and power electronics in the 2020-2025 timeframe, at $1.4 \mathrm{~kW} / \mathrm{kg}$ combined. An additional weight of 50 pounds was added to BEVs to account for the gearbox.

Battery weight was computed from an estimated battery specific energy $(\mathrm{kWh} / \mathrm{kg})$. Specific energy is not a fixed value but will vary depending on the power-to-energy $(\mathrm{P} / \mathrm{E})$ ratio of the battery and its gross capacity. Specific energy was provided by a dynamic link to ANL BatPaC, which computes specific energy as one of its outputs.

The "raw" PEV curb weights represented by Equations (4) and (5) are typically significantly larger than the curb weights of the conventional baseline vehicles on which they are based, because the added weight of the battery is typically greater than the weight delete. However, the potential battery cost savings may make PEV mass reduction more cost effective than that represented in the conventional baseline vehicle [13]. As an approximate but straightforward way to directionally account for this effect, we further constrained the iteration process by forcing $\mathrm{CW}_{\mathrm{BEV}}$ or $\mathrm{CW}_{\mathrm{PHEV}}$ for each vehicle to match the curb weight of the corresponding baseline vehicle ( $\left.\mathrm{CW}_{\text {base_reduced }}\right)$ [3]. To do so, we solved for the percentage of mass reduction that must be applied to the glider (a vehicle exclusive of powertrain) to offset the additional curb weight. In cases where more than 20 percent glider mass reduction would be needed to fully offset the difference, it was capped at 20 percent and only in these cases was the curb weight of the PEV allowed to be larger than that of its baseline counterpart [3]. The degree of applied mass reduction is tracked for each vehicle and its cost is included when estimating the total vehicle cost.

In theory, a similar result might have been attained by applying each mass reduction percentage to the glider itself and allowing the resulting total curb weights to be unconstrained. A different set of data points would have resulted, skewed toward cases with little or no mass reduction applied. However, because we expect that mass reduction in PEVs is attractive to manufacturers for its potential to reduce battery cost, data points representing little or no mass reduction are of limited interest. Generating a greater density of points at greater percentages of mass reduction would therefore align better with expected industry practice.

After determining the PEV curb weight (constrained in most cases to match the baseline curb weight, but with a specific degree of applied mass reduction to do so), the method then computes the loaded vehicle weight (also known as inertia weight or ETW) by adding 300 pounds to the curb weight [3]:

$$
\operatorname{ETW}_{\mathrm{PEV}}(l b)=\mathrm{CW}_{\mathrm{PEV}}(l b)+300
$$

The method then uses this test weight to develop an energy consumption estimate. First, it estimates the fuel economy (mi/gal) for a conventional light-duty vehicle of that test weight by a regression formula derived from the relationship between 2-cycle fuel economy and inertia weight. 
Compiled data on fuel economy vs. test weight from the EPA Trends Report [10] provided the primary data source. From this data, we derived a polynomial regression formula for fuel economy (mi/gal) as a function of ETW, as shown in Equation (7) [3].

$$
F E_{\text {conv }}(\mathrm{mi} / \mathrm{gal})=0.0000005308 \times E T W_{P E V^{2}}-0.0122335420 \times E T W_{P E V}
$$

An estimate of gross Wh/mile was then computed, assuming 33,700 Wh of energy per gallon of gasoline, as shown in Equation (8):

$$
E_{\text {gross_FTP }_{-}}(W h / m i)=\left(\frac{1}{F E_{\text {conv }}}\right) \times 33,700
$$

A series of adjustments was then applied representing assumed differences in energy losses between conventional vehicles and electrified vehicles (this effectively brings the figure into electrified vehicle space) [3]. Several powertrain efficiencies were estimated to assist in this conversion, including battery discharge efficiency, inverter and motor efficiency, transmission efficiency and other losses (such as wheel bearing, axle, and brake drag losses), and the percentage of energy delivered to the wheels that is used to overcome road loads (that is, the portion of wheel energy that is not later lost to friction braking) [3]. These efficiencies were selected based on engineering judgement and then optimized in a model calibration step to yield battery capacity estimates in line with the capacities seen in production PEVs of similar specifications.

Estimated road loads appropriate for PEVs were derived from those for conventional vehicles by accounting for reductions in aerodynamic drag and rolling resistance. It was assumed that PEVs would support drag and rolling resistance reductions of 20 percent relative model year 2008 baseline conventional vehicles. Based on simulation models used in the broader analysis, we estimated that a 20 percent reduction in each would reduce PEV road loads to approximately 90.5 percent of the baseline. The effect of reductions in curb weight were inherently represented by use of the ETW regression formula to convert curb weights into base energy consumption estimates [3].

The combined effect of these steps means that the estimated energy consumption of each PEV is derived from the energy consumption of a corresponding baseline conventional vehicle by applying a ratio of the road loads of the PEV (\%Roadload $\mathrm{P} / \mathrm{EV})$ to those of the baseline vehicle $\left(\%\right.$ Roadload $\left._{\mathrm{conv}}=1\right)$ and a ratio of the assumed efficiencies ( $\eta$ ) of the respective powertrains, as shown in Equation (9) [3].

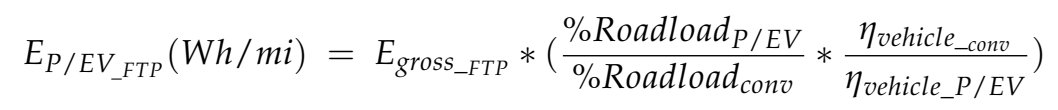

Equation (9) yields an unadjusted (laboratory), weighted, combined two-cycle (55\% FTP, 45\% HFET) estimate of energy consumption. To convert this to an estimated real-world energy consumption figure, the analysis applies a derating factor. Derating factors are discussed in a later section. As seen in Equation (10), where the derating factor is illustrated with a value of 70 percent as an example, applying the derating factor results in the PEV on-road energy consumption estimate that the method uses to determine the required battery pack capacity for the vehicle [3].

$$
E_{\text {onroad }}(\mathrm{Wh} / \mathrm{mi})=E_{P / E V_{-} F T P} *\left(\frac{1}{0.70}\right)
$$

Finally, as shown by Equation (11), the required battery energy capacity (BEC) is calculated as the on-road energy consumption ( $\mathrm{Wh} / \mathrm{mile}$ ) multiplied by the desired range (mi), divided by the usable battery capacity (the usable state-of-charge (SOC) design window). As discussed later, the assumed SOC design window (SOC\%) varied appropriately between BEVs and PHEVs [3].

$$
B E C(W h)=\frac{E_{\text {onroad }}\left(\frac{w h}{m i}\right) \times \operatorname{range}(m i)}{\operatorname{soc}^{2} \%}
$$


The iterative nature of the battery sizing problem means that all the preceding calculations are constructed in a spreadsheet as circular references and performed iteratively by the spreadsheet software until the estimated weights, sizes, and energy consumption figures converge [3].

\subsection{Selection of Primary Inputs}

Figure 1 (left of Figure) depicts the role of battery sizing assumptions and battery design assumptions in the model. Battery sizing assumptions include parameters that determine necessary battery power and capacity, such as vehicle weight, energy efficiency, usable capacity, specific energy, mass of motor and power electronics, motor power, allowances for power and capacity fade, and similar factors. Battery design assumptions include factors such as cell capacity, pack topology, cells per module, thermal medium, electrode aspect ratio and coating thickness, and manufacturing volume. These assumptions are reviewed in detail here.

\subsubsection{Inputs Influencing Battery Sizing}

One important input to the battery sizing process is the usable SOC design window. Based on observation of existing vehicles, we chose 90 percent for BEV200 and 85 percent for other BEVs. For PHEVs, a smaller window was assigned to beginning-of-life (BOL) and a somewhat larger window to end-of-life (EOL). Battery capacity was specified using the BOL figure, which effectively provides a buffer that can be used as the vehicle ages. The BOL SOC window for PHEV20 was placed at approximately 65 percent while the EOL window was placed at 75 percent. For PHEV40, the BOL window was 67 percent and the EOL window 77 percent. These figures were chosen by engineering judgement and by considering their effect on the ability of the sizing method to reproduce battery capacities of production PHEVs [3].

Another important input to the battery sizing process is the required power capability of the battery. Target battery power ( $10 \mathrm{~s}$ pulse) was set to 32 percent greater than the peak motor power, to account for losses in the motor $(10 \%)$ and EOL power fade (20\%). In the case of BEVs and many longer-range PHEVs, target capacity drove the design more than target power, such that the battery is sufficiently large that its natural power capability exceeds the target power. These batteries therefore would have enough power capability to support moderate levels of fast charging and provide a buffer against power fade [3].

In the analysis, PHEV40 was assumed to operate as a range-extended electric vehicle, which meant that the motor and battery would be sized to provide all-electric operation in all driving situations, and hence the PHEV40 range is all-electric. The battery and motor for PHEV20 were sized for blended-operation where it was assumed the engine could assist the motor during the charge depletion phase. All PHEVs were configured with a single propulsion motor, in contrast to some production PHEV designs that split the total power rating between two motors. While we acknowledge that most PHEVs include a second motor used primarily as a generator, the analysis did not assign a separate weight to this component but considered it as part of the weight of the conventional powertrain [3]. Although a PHEV application may allow some downsizing of the conventional portion of the powertrain, the analysis did not consider potential weight reductions from this source.

The derating factor also plays a role in determining battery size. The EPA range labeling rule allows manufacturers to determine the label range value either by applying a default 70 percent derating factor to a 2-cycle range test result, or to derive a custom derating factor by an optional process. According to EPA vehicle certification records for MY 2012-2016 BEVs, the vast majority of BEV models used the default 70 percent derating factor. The same data shows that Tesla Motors has elected the optional process for its BEV200+ vehicles resulting in a factor of nearly 80 percent for the standard Model $S$ ( 60 to $90 \mathrm{kWh}$ ), and from 73 to 76 percent for higher-performance and all-wheel-drive versions of the $S$ and $X$. We therefore adopted a derating factor of 75 percent for BEV200 and 70 percent for all other PEVs. 


\subsubsection{Inputs Influencing Battery Design}

User inputs to BatPaC were chosen as follows. For performance, battery power and energy requirements were derived from the battery sizing analysis described previously. Other considerations were battery chemistry, cell and module layout, and production volumes. The pack voltages, electrode dimensions, cooling capacity, and cell capacities that were output from BatPaC were confirmed to ensure consistency with current and expected industry practice. Because the overall analysis accounted for warranty costs separately, the warranty costs computed by $\mathrm{BatPaC}$ were deducted from the output costs.

For chemistry, we selected NMC622 cathode for BEV and PHEV40 packs, and a blended cathode (25 percent NMC333 and 75 percent LMO, the BatPaC default value) for PHEV20 packs, both with graphite anode. These selections were based on the known characteristics of the chemistries and their representation in current and near-term production vehicles.

Pack topology was optimized by choosing values for cells per module and number of modules to target a preferred cell capacity (in Ampere-hours). Since the number of modules per pack must be a whole number, varying the number of cells per module allows the number of cells per pack and their capacities to be better targeted. The number of cells per module were varied between 20 and 36 as needed to achieve target pack voltages and maximum cell capacities [2].

BEV cells were limited to a maximum capacity of $90 \mathrm{~A}-\mathrm{hr}$. Most were significantly smaller as only the larger BEV packs approached this limit. The BMW i3 $94 \mathrm{Ah}$ provides an example suggesting this can be an effective cell capacity in a BEV application. PHEV cells were limited to $60 \mathrm{~A}-\mathrm{hr}$. Electrode coating thickness was limited to 100 microns, which again was only approached by the largest BEV batteries. All packs were modeled with liquid glycol-water cooling. Pack voltages were limited to the approximate range of $300 \mathrm{~V}$ to $400 \mathrm{~V}$. Electrode aspect ratio was 3:1, supported by recent developments in pack design that suggest a movement toward low-profile packs that are mounted in the floor. BatPaC computed costs for a range of manufacturing volumes from 50,000 to 450,000 packs per year.

\section{Results}

\section{Battery Sizing and Cost Projections for Model Year 2025}

Table 1 shows projected curb weight and gross battery capacity for MY 2025 vehicles for the various PEV types and P2W classes. P2W classes are distinguished by relative power and weight, with Class 1 representing the smallest, least powerful vehicles. The two figures reported for each class represent the extremes of the range of values resulting from 0 to $20 \%$ target weight reduction. In comparing these figures to current production vehicles, it should be noted that these future vehicles in many cases reflect improvements in road load and efficiency that may not be present in some current vehicles.

Table 1. Projected gross battery capacity for MY 2025 by vehicle type, power-to-weight class, and range.

\begin{tabular}{|c|c|c|c|c|c|c|c|c|c|c|}
\hline & \multicolumn{2}{|c|}{$\begin{array}{c}\text { PHEV20 (25\% } \\
\text { NMC, } 75 \% \text { LMO) }\end{array}$} & \multicolumn{2}{|c|}{$\begin{array}{c}\text { PHEV40 } \\
\text { (NMC622) }\end{array}$} & \multicolumn{2}{|c|}{$\begin{array}{c}\text { BEV75 } \\
\text { (NMC622) }\end{array}$} & \multicolumn{2}{|c|}{$\begin{array}{c}\text { BEV100 } \\
\text { (NMC622) }\end{array}$} & \multicolumn{2}{|c|}{$\begin{array}{c}\text { BEV200 } \\
\text { (NMC622) }\end{array}$} \\
\hline & $\begin{array}{l}\text { Curb wt. } \\
\text { (lb) }\end{array}$ & $\begin{array}{l}\text { Gross } \\
\text { kWh }\end{array}$ & $\begin{array}{l}\text { Curb wt. } \\
\text { (lb) }\end{array}$ & $\begin{array}{l}\text { Gross } \\
\text { kWh }\end{array}$ & $\begin{array}{l}\text { Curb wt. } \\
\text { (lb) }\end{array}$ & $\begin{array}{l}\text { Gross } \\
\text { kWh }\end{array}$ & $\begin{array}{l}\text { Curb wt. } \\
\text { (lb) }\end{array}$ & $\begin{array}{l}\text { Gross } \\
\text { kWh }\end{array}$ & $\begin{array}{l}\text { Curb wt. } \\
\text { (lb) }\end{array}$ & $\begin{array}{l}\text { Gross } \\
\text { kWh }\end{array}$ \\
\hline \multirow{2}{*}{ Class 1} & 2571 & 6.2 & 2688 & 12.4 & 2295 & 16.4 & 2322 & 22.0 & 2506 & 37.9 \\
\hline & 2868 & 6.6 & 2868 & 12.9 & 2868 & 18.6 & 2868 & 24.8 & 2868 & 41.0 \\
\hline \multirow{2}{*}{ Class 3} & 3231 & 7.2 & 3391 & 14.5 & 2891 & 18.7 & 2928 & 25.1 & 3138 & 43.6 \\
\hline & 3613 & 7.8 & 3613 & 15.3 & 3613 & 22.1 & 3613 & 29.4 & 3613 & 48.7 \\
\hline \multirow{2}{*}{ Class 4} & 3644 & 7.9 & 3851 & 16.2 & 3249 & 20.3 & 3292 & 27.3 & 3519 & 47.6 \\
\hline & 4062 & 8.8 & 4048 & 16.9 & 4062 & 24.6 & 4062 & 32.9 & 4062 & 54.4 \\
\hline Class 5 & 4377 & 9.5 & 4643 & 19.8 & 3934 & 23.9 & 4008 & 32.4 & 4325 & 56.8 \\
\hline
\end{tabular}


Table 2 shows the range in projected cost per kWh for each MY 2025 PEV type and P2W class at a production volume of 450,000 packs per year. It is well known that battery cost, when expressed on a cost per $\mathrm{kWh}$ basis, is sensitive to total pack capacity and power-to-energy $(\mathrm{P} / \mathrm{E})$ ratio. Accordingly, the costs for these packs, for which designs and costs were determined by BatPaC, reflect these trends, with the highest specific cost per kWh projected for smaller PHEV20s and the lowest specific cost for larger BEV200s.

Table 2. Projected pack-level direct manufacturing costs for MY 2025 by vehicle type and range (\$/kWh, 2015\$).

\begin{tabular}{lccccc}
\hline & PHEV20 & PHEV40 & BEV75 & BEV100 & BEV200 \\
\hline Class 1 & $371-388$ & $250-258$ & $205-223$ & $173-185$ & $145-151$ \\
Class 2 & $352-365$ & $242-251$ & $193-211$ & $165-177$ & $137-144$ \\
Class 3 & $337-361$ & $237-247$ & $186-205$ & $159-172$ & $133-140$ \\
Class 4 & $319-346$ & $232-246$ & $176-204$ & $155-165$ & $126-134$ \\
Class 5 & $277-309$ & $227-241$ & $160-189$ & $146-155$ & $115-124$ \\
\hline
\end{tabular}

\section{Discussion}

\subsection{Validation of Battery Sizing}

Here we assess the effectiveness of the battery sizing methodology by comparing the battery capacities in production vehicles to those that would be predicted by the methodology for their respective curb weights, driving ranges, and derating factors used in certification. As shown in Table 3, the methodology predicts capacities quite close to those seen in several existing BEVs.

Table 3. Comparison of projected capacities to those of selected production vehicles.

\begin{tabular}{ccccccc}
\hline Example & Range (mi) & Curb Weight (lb) & Derate Factor & Gross kWh & Projected Gross kWh & Error \\
\hline Nissan Leaf & 107 & 3340 & 0.70 & 30 & 30.3 & $1 \%$ \\
Chevy Bolt & 238 & 3580 & 0.70 & 60 & 61.6 & $3 \%$ \\
Model S P85D & 253 & 4963 & 0.738 & 85 & 88.75 & $4 \%$ \\
Model S 60 & 210 & 4323 & 0.796 & 60 & 57.5 & $-4 \%$ \\
Model S 85 & 265 & 4647 & 0.796 & 85 & 84 & $-1 \%$ \\
\hline
\end{tabular}

One uncertainty affecting the comparison is the true usable capacity of each vehicle, as compared to our assumptions of 90 percent for BEV200 and 85 percent for other BEVs. Manufacturers do not consistently publish usable capacity and it is difficult to verify the accuracy of reported values. Another uncertainty is the true gross capacity, for which reported values may be similarly imprecise. Differences in vehicle efficiency from our assumptions may also affect the comparison.

Figure 3 illustrates another perspective aggregated over a larger population of examples. The battery capacities of actual and projected vehicles are normalized to curb weight, which more directly expresses the efficiency with which a vehicle of a given weight converts gross battery capacity to miles of label range. In the figure, the battery capacity per unit curb weight $(\mathrm{kWh} / \mathrm{kg})$ of comparable production BEVs is compared against that of comparable MY 2016-2017 production BEVs. A 75 percent range derating factor is assumed for BEV200+ vehicles (the plotted range of production vehicles that certified with a different derating factor was adjusted to represent what their range would have been if they had certified using a 75 percent factor. It can be seen that the predicted BEV battery capacities closely follow the trend line established by comparable MY 2016-2017 BEVs. Results for PHEVs were similar. 


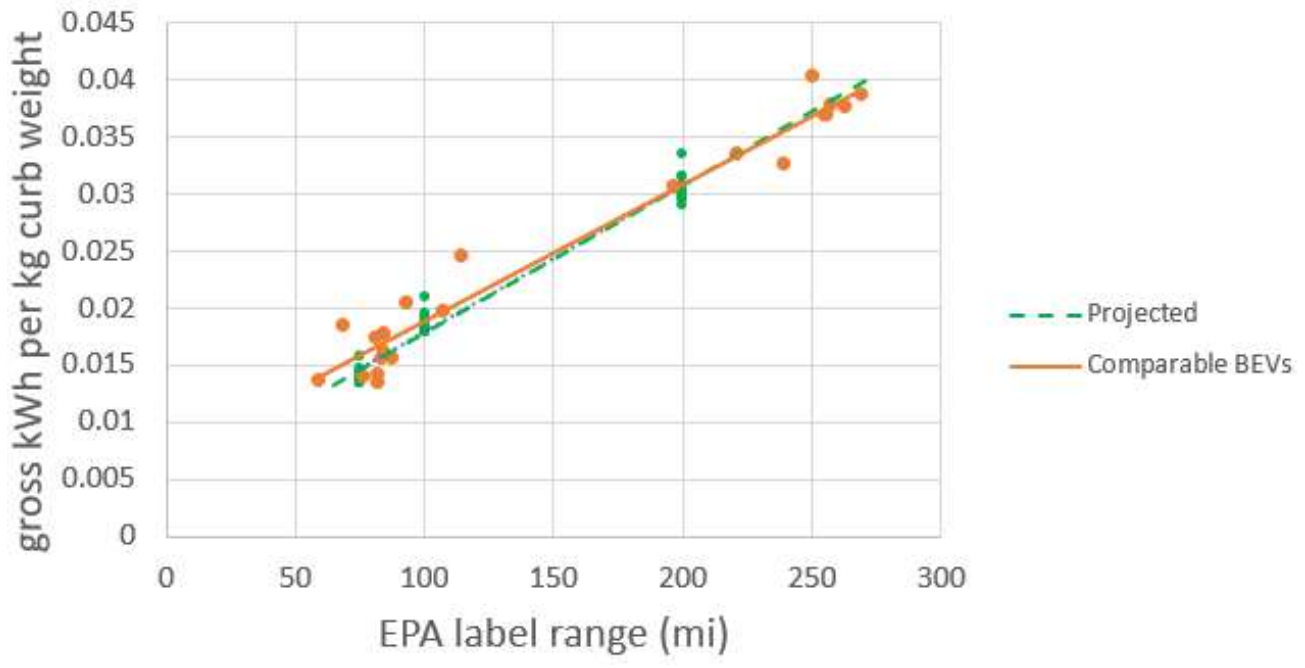

Figure 3. Projected BEV gross battery capacity per unit curb weight compared to comparable production BEVs [3].

On close examination of the plot, it can be seen that for vehicles with shorter ranges, such as BEV75, BEV100, and PHEV20 (not shown), the trend line for projected capacity runs slightly below the trend line of production vehicles, as the methodology is tuned to predict future capacities for these vehicles somewhat smaller (on average) than are currently found in MY 2012-2017 production vehicles. This reflects our expectation that vehicles from that time frame that were marketed with a short range (which in the figure are represented largely by relatively low-production examples from a diversity of manufacturers) may tend to embody a lesser degree of optimization than the longer-range data points which represent higher-production examples from a smaller group of other manufacturers (Tesla and General Motors). In other words, we expect a slightly greater potential for future powertrain efficiency improvement to remain for these shorter-range vehicles than for longer-range vehicles, relative their current state.

\subsection{Validation of Cost}

It is important to reiterate that battery costs are affected by many influences, and future projections are subject to uncertainty. Comparing one set of projections to those from other sources requires a full understanding of the factors considered by each source. As a first-level comparison, here we compare our projected costs to two widely reported sources that are commonly cited in similar comparisons in the literature.

\subsubsection{Estimating Pack Costs from Cell Costs}

One way to validate cost estimates is to compare them to examples of actual costs. Cost at a pack level is rarely disclosed publicly but is sometimes encountered at the cell level. Here we develop a basis for comparing cell costs to pack costs to enable a comparison to the pack costs estimated here.

We collected several sources that suggest a ratio of total pack cost to constituent cell cost, or that allow such a ratio to be derived [14-20]. Further detail on our use of these sources is provided at pp. 5-124 of [2]. As seen in Table 4, most of these sources suggest a ratio of about 1.25 to 1.4.

To further inform this issue, we derived pack-to-cell ratios from costs estimated by BatPaC for a pack configured similarly to that of the Chevy Bolt. The Bolt pack is $60 \mathrm{kWh}$, arranged 96S3P in ten modules with a varying number of cells per module. Because $\mathrm{BatPaC}$ requires a fixed number of cells per module, we modeled 100S3P in ten modules of 30 cells using NMC622-G chemistry at annual production of 100,000 packs and a target $10 \mathrm{~s}$ pack power of $100 \mathrm{~kW}$. Figure 4 shows the ratio of pack cost to cell cost for various pack capacities of this construction and suggests a factor of about 1.3 would apply to a $60-\mathrm{kWh}$ pack. 
Table 4. Ratios of total pack cost to cell cost suggested by information in published sources.

\begin{tabular}{cc}
\hline Source & Ratio \\
\hline Kalhammer et al. [14] & $1.24-1.4$ \\
Element Energy [15] & $1.6-1.85$ \\
Konekamp [16] & 1.29 \\
USABC [17] & 1.25 \\
Tataria/Lopez [18] & 1.26 \\
Keller [19] & 1.2 \\
UBS [20] & $1.32-1.44$ \\
\hline
\end{tabular}

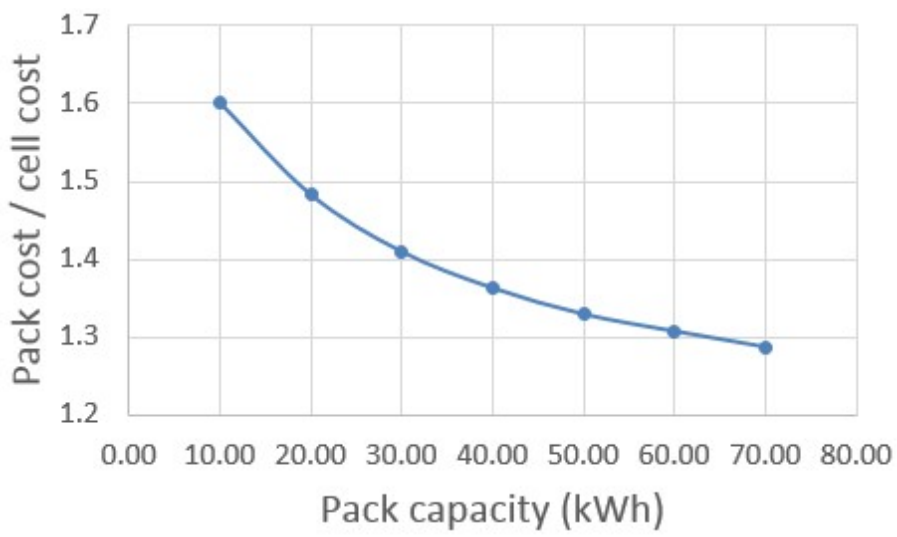

Figure 4. Ratio of pack cost to cell cost computed by BatPaC for pack topology similar to Chevy Bolt.

\subsubsection{Comparison of Projected Costs to Other Sources}

In October 2015, General Motors (GM) publicly commented on its cell costs for the Chevy Bolt BEV [21]. These costs have been widely reported in the literature and are frequently cited in comparison to future projections. GM reported a cell cost of $\$ 145$ per $\mathrm{kWh}$ for 2015 to 2019, dropping to $\$ 120$ per $\mathrm{kWh}$ in 2020 and to $\$ 100$ per $\mathrm{kWh}$ in 2022. Assuming cell-to-pack factors of 1.3 and 1.5, the 2015-2019 figure would translate to $\$ 190$ to $\$ 220$ per $\mathrm{kWh}$ on a pack level, while the figures for 2020 and 2022 would translate to $\$ 156-\$ 180$ and $\$ 130-\$ 150$ per $\mathrm{kWh}$, respectively. Our estimates for BEV200 pack cost, which range from approximately $\$ 120$ to $\$ 150$ per $\mathrm{kWh}$ and which we attribute to 2025 , compare well to the 2022 pack-converted costs of $\$ 130-\$ 150$ per $\mathrm{kWh}$.

The analysis described in this paper generated costs only for the year 2025 and only for the six P2W classes modeled. These costs acted as inputs to a downstream analysis (not described in this paper) that generated costs for intervening years by applying a reverse learning curve based on a range of production volumes, for a group of specific PEV technology packages corresponding to the 29 vehicle classes considered in the broader analysis. The yearly estimates resulting from these curves were ultimately used to project PEV vehicle costs in the broader analysis and are somewhat more conservative on a cost per kWh basis as compared to the raw 2025 costs reported in Table 2.

Figure 5 compares the yearly cost estimates for the various P2W classes of BEV200 to the pack-converted GM costs. Our estimates appear consistent with or somewhat conservative relative the trend established by the estimated GM cost (converted to pack-level cost). 


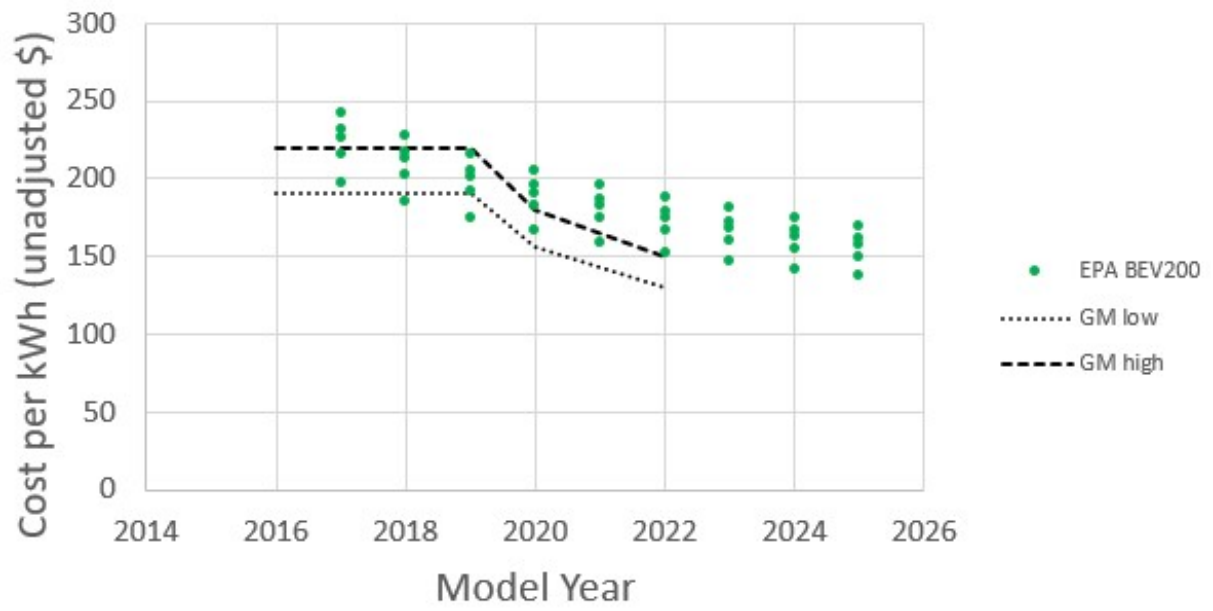

Figure 5. Comparison of Estimated Pack-Converted Chevy Bolt Costs to Post-Processed BEV200 estimates.

As a further comparison, Figure 6 plots our estimated costs for larger packs (PHEV40 to BEV200) against the survey of published future cost estimates reported by Nykvist and Nilsson [22]. Our estimated costs for these packs also lie within the range of future cost trends suggested by this survey.

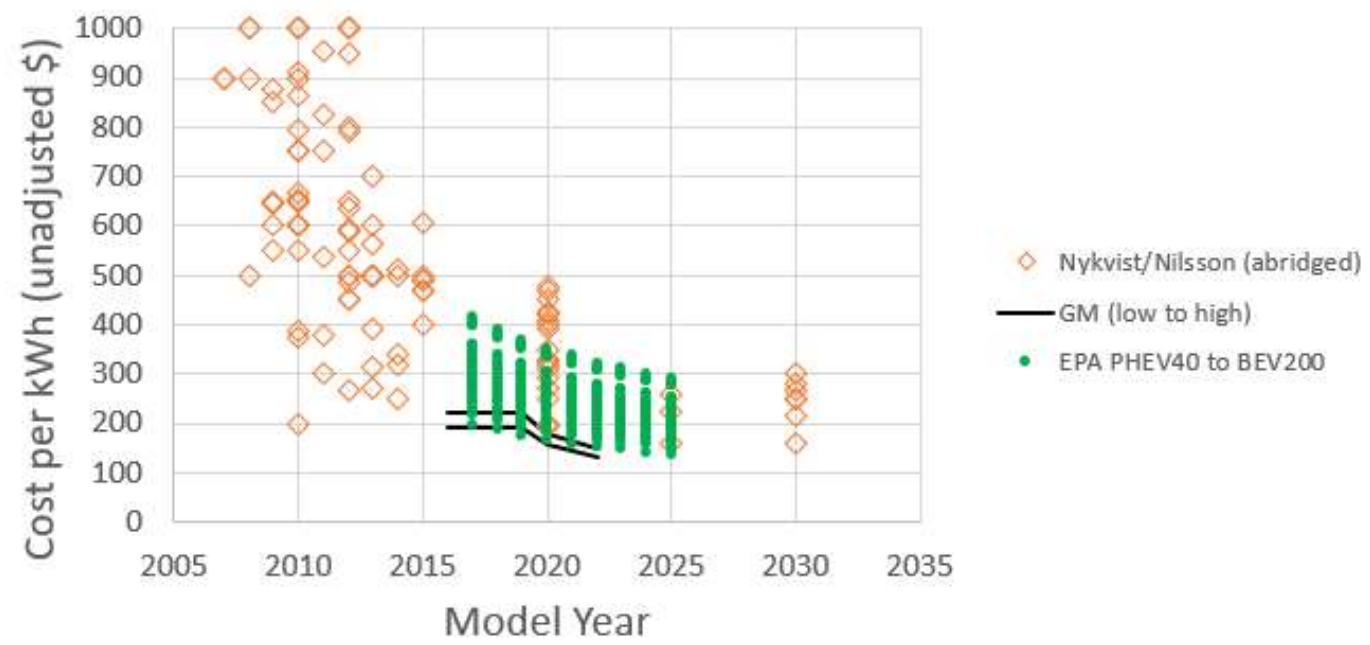

Figure 6. Comparison of Estimated Costs to Nykvist \& Nilsson trends [22].

\section{Conclusions}

We outlined a spreadsheet-based method to project battery gross capacities, motor and battery power ratings, and battery costs for an array of future PEVs. A relationship between 0-60 time and the power rating of the electric drive motor was derived from empirical data. A range of cost ratios between total pack cost and constituent cell cost was derived from published sources and BatPaC output data to assist in the comparison of cell costs to pack costs. The projected battery capacities appear to align well with trends established by production PEVs in the market. Projected costs for BEV200 appear consistent with widely cited cell costs for a production BEV, and projected costs for PHEV40 and BEVs appear consistent with trends described in the literature.

Supplementary Materials: Supporting data is available online at Regulations.gov, in EPA Docket EPA-HQ-OAR-2015-0827. For chart data, search for Docket Item “EPA-HQ-OAR-2015-0827-5788” titled Data and Charts for Selected Figures in Electrification Chapters of Proposed Determination TSD and see Microsoft Excel attachment to that entry. For BatPaC modeling data, search for "EPA-HQ-OAR-2015-0827-5824" and follow the instructions given therein to locate and examine the source data. 
Author Contributions: Conceptualization, B.E. and J.M; Methodology, B.E., M.S. and J.M.; Investigation, Validation, and Formal Analysis, M.S.; Resources, J.M.; Writing-Original Draft Preparation, M.S.; Writing-Review \& Editing, J.M.

Funding: This research received no external funding.

Acknowledgments: The authors would like to acknowledge Kevin Gallagher, Shabbir Ahmed, Paul Nelson and Dennis Dees of Argonne National Laboratory for their roles in conceptualizing and developing the BatPaC model.

Conflicts of Interest: The authors declare no conflict of interest.

\section{References}

1. U.S. Code of Federal Regulations. Federal Register (77 FR 62624); U.S. Code of Federal Regulations: New York, NY, USA, 15 October 2012.

2. U.S. Environmental Protection Agency. Draft Technical Assessment Report: Midterm Evaluation of Light-Duty Vehicle Greenhouse Gas Emission Standards and Corporate Average Fuel Economy Standards for Model Years 2022-2025; EPA-420-D-16-900; U.S. Environmental Protection Agency: Washington, DC, USA, July 2016.

3. U.S. Environmental Protection Agency. Proposed Determination on the Appropriateness of the Model Year 2022-2025 Light-Duty Vehicle Greenhouse Gas Emissions Standards under the Midterm Evaluation: Technical Support Document; EPA-420-R-16-021; U.S. Environmental Protection Agency: Washington, DC, USA, November 2016.

4. U.S. Environmental Protection Agency. Final Determination on the Appropriateness of the Model Year 2022-2025 Light-Duty Vehicle Greenhouse Gas Emissions Standards under the Midterm Evaluation; EPA-420-R-17-001; U.S. Environmental Protection Agency: Washington, DC, USA, January 2017.

5. Nelson, P.A.; Gallagher, K.G.; Bloom, I.D.; Dees, D.W. Modeling the Performance and Cost of Lithium-Ion Batteries for Electric Drive Vehicles, 2nd ed.; ANL-12/55; Argonne National Laboratory: Argonne, IL, USA, December 2012.

6. Regulations.gov. Search for Docket Item "EPA-HQ-OAR-2015-0827-5824". Instructions for Accessing EPA Battery Analysis (Proposed Determination). Docket EPA-HQ-OAR-2015-0827. Available online: http:/ / www.regulations.gov (accessed on 6 October 2018).

7. Nelson, P.A.; Santini, D.J.; Barnes, J. Factors Determining the Manufacturing Costs of Lithium-Ion Batteries for PHEVs. In Proceedings of the 24th World Battery, Hybrid and Fuel Cell Electric Vehicle Symposium and Exposition EVS-24, Stavanger, Norway, 13-16 May 2009.

8. Santini, D.J.; Gallagher, K.G.; Nelson, P.A. Modeling the Manufacturing Costs of Lithium-Ion Batteries for HEVs, PHEVs, and EVs. In Proceedings of the 25th World Battery, Hybrid and Fuel Cell Electric Vehicle Symposium and Exposition EVS-25, Shenzhen, China, 5-9 November 2010.

9. ICF International. Modeling the Cost and Performance of Lithium-Ion Batteries for Electric-Drive Vehicles; Peer Review Report of the Draft Report; ICF International: Denver, CO, USA, 31 March 2011.

10. U.S. Environmental Protection Agency. Light-Duty Automotive Technology, Carbon Dioxide Emissions, and Fuel Economy Trends: 1975 through 2016; U.S. Environmental Protection Agency: Washington, DC, USA, December 2016.

11. Malliaris, A.C.; Hsia, H.; Gould, H. Concise Description of Auto Fuel Economy and Performance in Recent Model Years; Society of Automotive Engineers: Warrendale, PA, USA, 1976.

12. USCAR: U.S. DRIVE. Available online: http://www.uscar.org/guest/partnership/1/us-drive (accessed on 6 October 2018).

13. Ward, J.; Gohlke, D.; Nealer, R. The Importance of Powertrain Downsizing in a Benefit-Cost Analysis of Vehicle Lightweighting. JOM 2017, 69, 1065-1070. [CrossRef]

14. Kalhammer, F.R.; Kopf, B.M.; Swan, D.H.; Roan, V.P.; Walsh, M.P. Status and Prospects for Zero Emissions Vehicle Technology; Report of the ARB Independent Expert Panel 2007; State of California Air Resources Board: Sacramento, CA, USA, 2007.

15. Element Energy. Cost and Performance of EV Batteries: Final Report for The Committee on Climate Change. 21 March 2012. Available online: http:/ /www.element-energy.co.uk/wordpress/wp-content/uploads/ 2012/06/CCC-battery-cost_-Element-Energy-report_March2012_Finalbis.pdf (accessed on 6 October 2018).

16. Konekamp, A. The Tesla Model S Battery: A Battery Pack Analysis Study. In Proceedings of the 2015 Advanced Automotive Battery Conference, Detroit, MI, USA, 15-19 June 2015.

17. U.S. Advanced Battery Consortium. USABC Goals for Advanced Batteries for EVs-CY 2020 Commercialization. Available online: http:/ / www.uscar.org/commands/files_download.php?files_ $\mathrm{id}=364$ (accessed on 6 October 2018). 
18. Tataria, H.; Lopez, H.A. EV Battery Development (Envia Systems). In Fiscal Year 2013 Annual Progress Report for Energy Storage RED; DOE/EE-1038; U.S. Department of Energy: Washington, DC, USA, February 2014.

19. Keller, G. DOE's Efforts to Develop Hybrid Powertrain technologies for Heavy-Duty Vehicles. In Proceedings of the 2015 SAE Hybrid \& Electric Vehicle Technologies Symposium, San Diego, CA USA, 10-12 February 2015.

20. UBS Limited. UBS Evidence Lab Electric Car Teardown Disruption Ahead? UBS Limited: London, UK, 2017.

21. General Motors Corporation. General Motors 2015 Global Business Conference. Presentation. 1 October 2015. Available online: http:/ / www.slide52 in2015_GBC_Combined_PDF_v3.pdf (accessed on 6 October 2018).

22. Nykvist, B.; Nilsson, M. Rapidly Falling Costs of Battery Packs for Electric Vehicles. Nat. Clim. Chang. 2015. [CrossRef]

(C) 2018 by the authors. Licensee MDPI, Basel, Switzerland. This article is an open access article distributed under the terms and conditions of the Creative Commons Attribution (CC BY) license (http:/ / creativecommons.org/licenses/by/4.0/). 